Provided for non-commercial research and education use. Not for reproduction, distribution or commercial use.

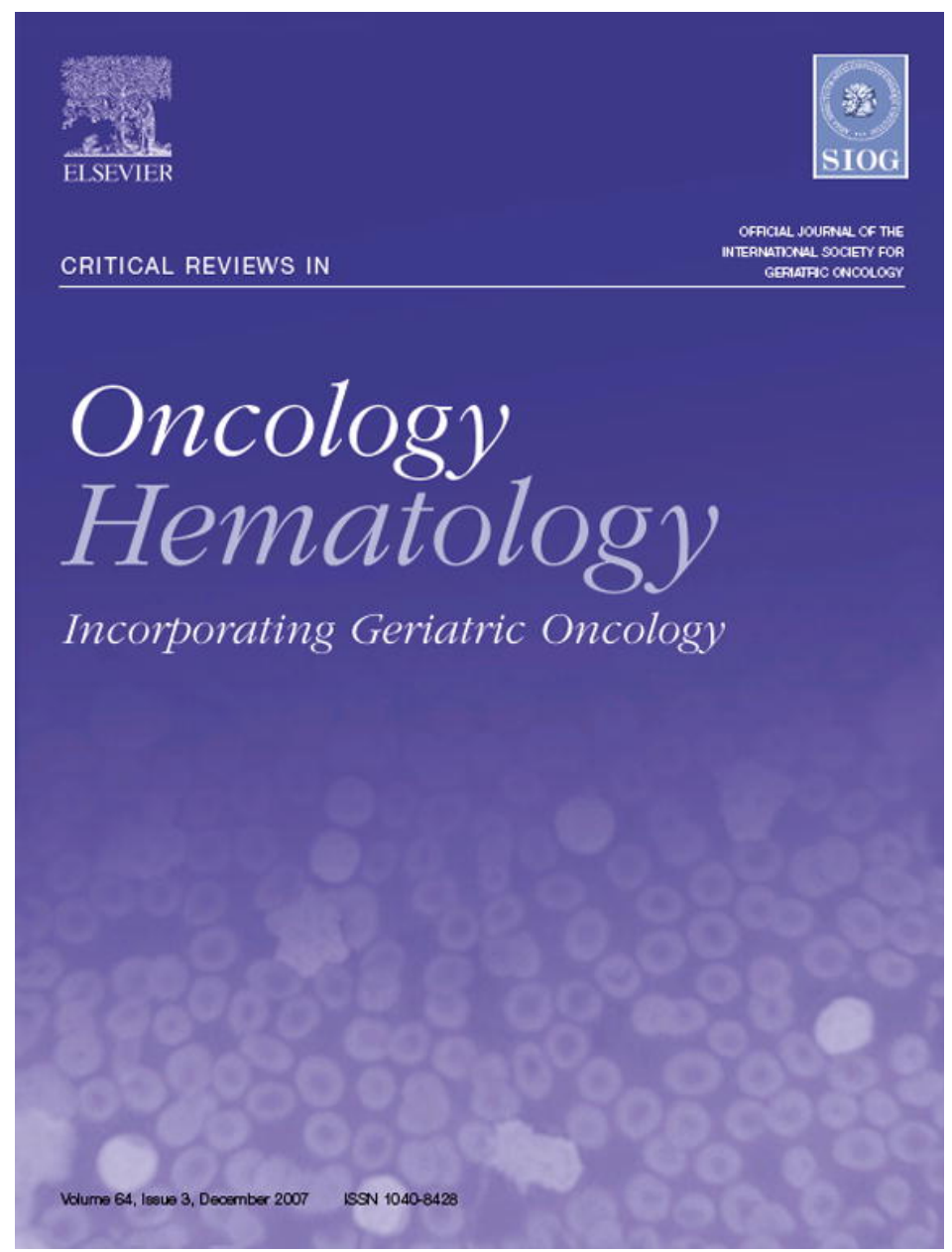

This article was published in an Elsevier journal. The attached copy

is furnished to the author for non-commercial research and education use, including for instruction at the author's institution, sharing with colleagues and providing to institution administration.

Other uses, including reproduction and distribution, or selling or licensing copies, or posting to personal, institutional or third party websites are prohibited.

In most cases authors are permitted to post their version of the article (e.g. in Word or Tex form) to their personal website or institutional repository. Authors requiring further information regarding Elsevier's archiving and manuscript policies are encouraged to visit:

http://www.elsevier.com/copyright 


\title{
Attitudes towards predictive genetic testing in minors for familial breast cancer: A systematic review
}

\author{
Pascal Borry*, Louise Stultiëns, Herman Nys, Kris Dierickx \\ Centre for Biomedical Ethics and Law, Katholieke Universiteit Leuven, Belgium
}

Accepted 26 April 2007

\section{Contents}

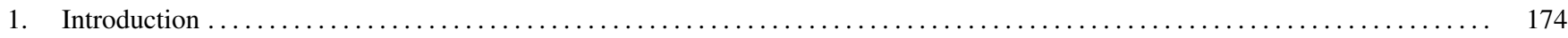

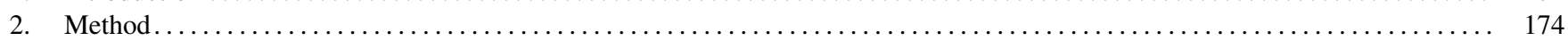

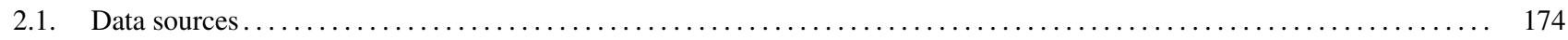

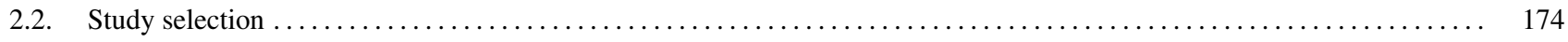

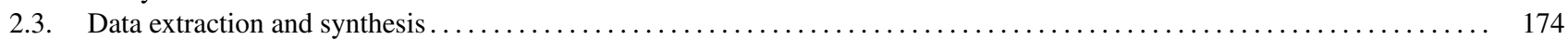

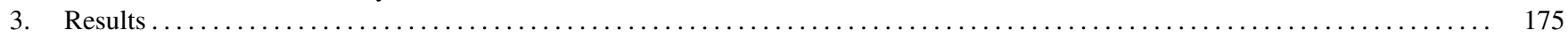

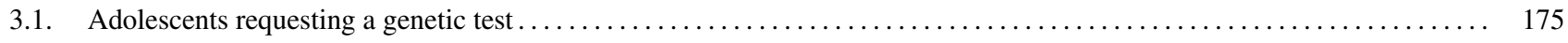

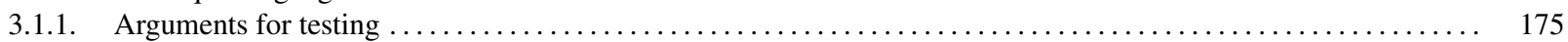

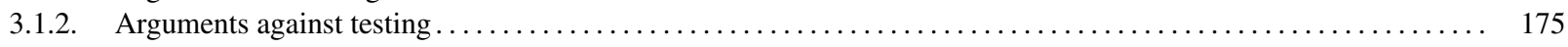

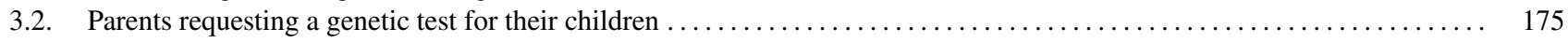

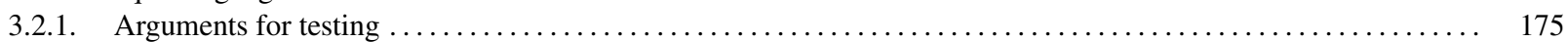

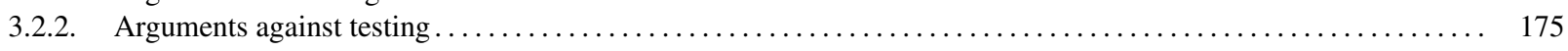

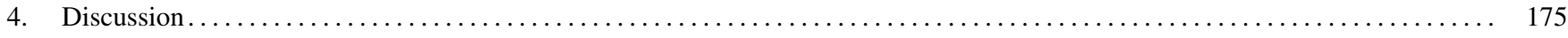

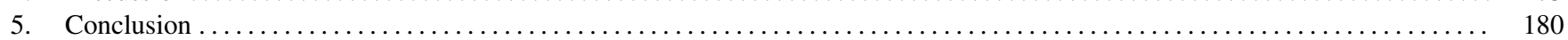

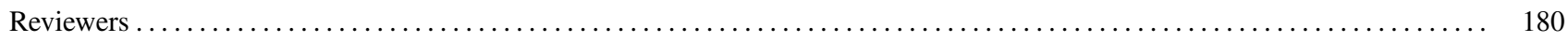

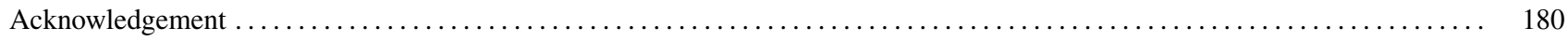

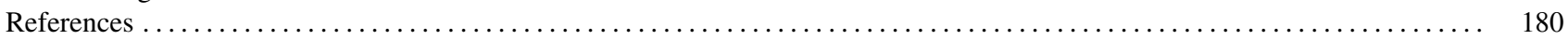

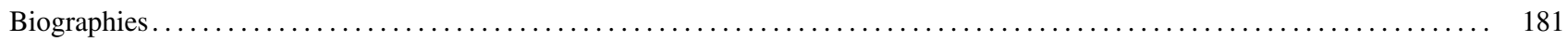

\begin{abstract}
Objectives: The objective of this article is to review the attitudes of different stakeholders (minors, parents, healthcare professionals, and relatives of affected individuals) towards predictive genetic testing of minors for familial breast cancer.

Design: The databases PubMed, Google Scholar, Psychinfo, Biological Abstracts, Francis, Anthropological Index online, Web of Science, and Sociological Abstracts were searched using relevant key words; literature indexed up to May 2006 was considered. Studies were included if they were published in a peer-reviewed journal written in English and if they described the attitudes of the different stakeholders towards predictive genetic testing of minors for familial breast cancer. The results are presented in a summary form.

Results: A total of 14 studies were included. The studies were very heterogeneous, using a variety of study populations, study designs, sample sizes, and study measures. Substantial proportions of adolescents were interested in learning whether they were at risk for familial breast cancer. The attitudes of healthcare professionals about testing minors diverged.

Conclusion: Our review has made clear that many respondents fail to understand potential risks related to predictive genetic testing in minors. Respondents might have overly positive expectations about possibilities for genetic testing. This emphasizes the need for genetic education and counselling about genetic testing in minors.
\end{abstract}

(c) 2007 Elsevier Ireland Ltd. All rights reserved.

Keywords: Cancer; Oncology; Genetic; Minors; Review no competing interests

\footnotetext{
* Corresponding author at: Centre for Biomedical Ethics and Law, Kapucijnenvoer 35/3, Box 7001, 3000 Leuven, Belgium. Tel.: +32 16 336951 ; fax: +3216336952.

E-mail address: Pascal.Borry@med.kuleuven.be (P. Borry).
} 


\section{Introduction}

Hereditary breast cancer accounts for approximately $5-10 \%$ of all breast cancer cases and often includes mutations of the two breast cancer susceptibility genes, BRCA1 and BRCA2. Women born with mutations in either BRCA1 or BRCA2 are at significantly higher risk of developing breast and ovarian cancer than are women in the general population, but the magnitude of risk to women in the former group is controversial [1]. Studies have shown that mutations in BRCA1 are associated with up to an $87 \%$ risk of breast carcinoma by the age of 70 years; and besides the life-time risk, mutations of the BRCA1 and BRCA2 tumour suppressor genes increase the risk of early onset breast carcinoma. BRCA1 mutation carriers have an $18 \%$ risk (15\% for BRCA2 mutation carriers) for developing breast cancer before the age of 39 years, and the risk increases to 59\% (BRCA2 34\%) at ages $40-49$ years. The cumulative risk is estimated to be $3.2 \%$ by the age of 30 years [1,2].

For adult women in an at-risk family, identification of cancer-predisposing mutations is a necessary first step towards improved treatment and prevention. Hereditary breast cancer is inherited in an autosomal-dominant way; i.e., a woman with an abnormal BRCA susceptibility gene has a $50 \%$ chance of passing that gene on to her children. Women in this situation are therefore confronted with the reality that their children might develop breast cancer at some point in their lives. If these children have not reached legal age, the parents might raise the question whether genetic testing for breast cancer susceptibility genes in minors is useful. However, unlike testing for other cancers for which preventive or therapeutic strategies exist (e.g., Li Fraumeni syndrome, familial adenomatous polyposis, or Von Hippel-Lindau), having information about one's BRCA1/2 mutation status before reaching the legal adult age is not considered medically necessary for disease prevention or early detection. Guidelines for the early detection of breast cancer advise that testing should begin no earlier than the age of 20 years, recommending surveillance techniques such as breast self-examination and clinical breast examination [3]. Existing guidelines also stress that genetic testing should be offered at the moment health benefits expand but should not be offered before that time. Predictive genetic testing is recommended only when "established, effective, and important medical treatment" [4] can be offered or when testing "provides scope for treatment which to any essential degree prevents, defers or alleviates the outbreak of disease or the consequences of the outbreak of disease" [5]. The rationale behind this option is that predictive testing in minors for adult-onset disease "should be delayed until the person is old enough to make an informed choice" [6]. In addition, early identification of a breast cancer susceptibility gene in minors is associated with psychological, social, and ethical concerns [7].

The objective of this article is to provide a systematic and detailed review of the attitudes of minors, parents, relatives of affected individuals and healthcare professionals towards predictive genetic testing for breast cancer. We will specifically investigate what these stakeholders consider as the preferred or ideal age for such testing and the reasons they advance to support their position. We will analyze whether the position recommended in the reviewed guidelines is shared by the various stakeholders. Little is known about the extent to which the parties involved agree on the professional recommendations concerning cancer susceptibility testing. For the sake of clarity, we define minors as all persons who have not reached legal age (which in most countries is 18 years). What distinguishes children from adolescents is the gradual development of a child's cognitive skills and moral reasoning and the fact that "as children progress through successive states of development, they become capable of greater participation in decisions about their own welfare" [8]. When discussing adolescents, we refer to minors who are "able to participate in the decision as an autonomous individual" [9], or minors who have "decision making capacity" [10]. When discussing children, we refer to minors who are considered to be unable to do so.

\section{Method}

\subsection{Data sources}

We searched the databases PubMed, Google Scholar, Psycinfo, Biological Abstracts, Francis, Eric, Anthropological Index Online, Web of Science, and Sociological Abstracts, using one of the following keywords attitude, view, survey, questionnaire, responses, opinions, beliefs, interview, perspectives, reasoning, focus groups, convictions, values, ideas, emotions, thoughts, feelings; the actual search used the keyword in truncated form in combination with the terms BRCA or breast or ovarian. In addition, a referral to minors was also examined through the following keywords child, childhood, adolescent, infant, young, minor, pediatric or paediatric. Relevant references within pertinent articles were also consulted. The search included literature indexed up to May 2006.

\subsection{Study selection}

The abstracts of the retrieved articles were read, and studies were included for further consideration if they were published in a peer-reviewed journal appearing in English, and if they reported the attitudes of minors, parents, relatives of affected individuals, or healthcare professionals towards predictive genetic testing for breast cancer in minors. Studies that described attitudes towards population screening in minors were excluded. Quantitative as well as qualitative studies were included.

\subsection{Data extraction and synthesis}

As there was considerable heterogeneity in populations studied and measures used in candidate articles, we consid- 
ered it inappropriate to pool the data in a meta-analysis and instead present them in summary form.

\section{Results}

We identified 14 studies about attitudes towards genetic testing for hereditary breast cancer in minors. These studies were very heterogeneous and used a variety of study populations, study designs, samples sizes, and study measures. The quality of the studies also varied. An overview of the studies is presented in Table 1. In Table 2, we describe the attitudes towards predictive genetic testing for breast cancer in minors and summarize the questions asked and the responses to these questions. Various studies distinguished two different situations: [1] the case of adolescents requesting a genetic test for BRCA, and [2] the case of parents requesting such a test for their children. Based on these studies, we provide an overview of the arguments used for and against such testing in both cases. It is not our aim to make a qualitative appraisal of every argument or to describe how many persons defend these arguments.

\subsection{Adolescents requesting a genetic test}

\subsubsection{Arguments for testing}

Three main arguments were described in favour of providing a predictive genetic test for hereditary breast cancer upon the request of adolescents. Firstly, various healthcare professionals argued that adolescents can be considered competent and able to give consent to treatment or investigation [11-13]. Secondly, various stakeholders referred to the potential psychological benefit. A clinical geneticist mentioned that genetic testing in minors can lead to "potential reassurance and potential lifestyle chances, usage of the contraceptive pill and planning" [11]. Some midwives and nurses mentioned such benefits as planning life better, removing uncertainty, and preparing oneself psychologically [13]. Especially mothers who had breast cancer or who were at increased risk for breast cancer emphasized psychological benefits that might stem from relief associated with a negative test result [14]. Thirdly, some studies referred to the medical benefit of early detection and preventive measures [13-16]. In a survey of adolescents, girls wishing to be tested stated that, in the event of a positive result, they would submit to frequent breast examinations (83\%) and to early mammograms (74\%) [15].

\subsubsection{Arguments against testing}

Four main arguments were described against genetic testing upon the request of adolescents. Firstly, some healthcare professionals indicated that they would require both the consent of the parents and the adolescent before proceeding with genetic testing [12]. Secondly, various studies referred to the potential negative psychological consequences of genetic testing for breast cancer in adolescence. Some clinical geneticists feared that testing could affect the self-image of the adolescent if the test result was positive [11]. Various studies reported that respondents feared that testing could lead to increased anxiety or stress in adolescents undergoing testing [13-16]. Also, one study reported substantial concern about potential stigmatization [14]. Thirdly, various studies reported that respondents felt that there were no immediate medical benefits in performing predictive genetic testing in minors for breast cancer. As a clinical geneticist puts it: "She is likely to have 10-20 years before it does become imminent and circumstances may have dramatically changed by then. It is hard to see how any immediate decisions, for example, life plans, would be influenced by knowledge of carrier status at $15 \ldots$ Her risk is negligible at this age". In an interview study, mothers who had breast cancer before the age of 50 years or who were at increased risk for breast cancer questioned the value of having genetic test results in the absence of an effective intervention [14]. In the absence of immediate medical benefits, some clinical geneticists advised "more time for reflection" [11]. Some adolescents considered themselves also "too young to get tested" $[14,15]$. Fourthly, some clinical geneticists referred to the fact that testing might lead to a 'slippery slope': "Thin end of wedge. Why not a mature 12 year old?" [11].

\subsection{Parents requesting a genetic test for their children}

\subsubsection{Arguments for testing}

Three main arguments were described in favour of performing a genetic test upon the request of parents. Firstly, in some studies some respondents referred to the advantages of early detection and the start of preventive measures (breast self-examinations, clinical breast examinations, or diet modification) at an early age $[13,17,18]$. Secondly, some midwives and nurses referred to the fact that testing in childhood can remove uncertainty, can prepare the child psychologically, or can prepare the child for the future [13]. Thirdly, some midwives and nurses referred to parents' right to know, because it is about the health of their own child [13].

\subsubsection{Arguments against testing}

Three main arguments were described against genetic testing for inherited cancer-predisposing mutations. Firstly, some studies referred to the absence of immediate medical benefits and the potential for many healthy years before medical implications may appear $[13,18,19]$. Secondly, some midwives and nurses indicated that knowing one's carrier status can lead to added psychological burden on the child and the parents, a dark future, and a danger of stigmatization [13]. Thirdly, some studies referred to personal autonomy, a child's right not to know, and a child's right to decide later in life $[13,18,19]$.

\section{Discussion}

Substantial proportions of adolescents were interested in learning whether they are at risk for familial breast cancer 
Table 1

Aim, design, methods, measures and limitations of studies assessing the attitudes towards predictive testing in minors with a family history of breast cancer

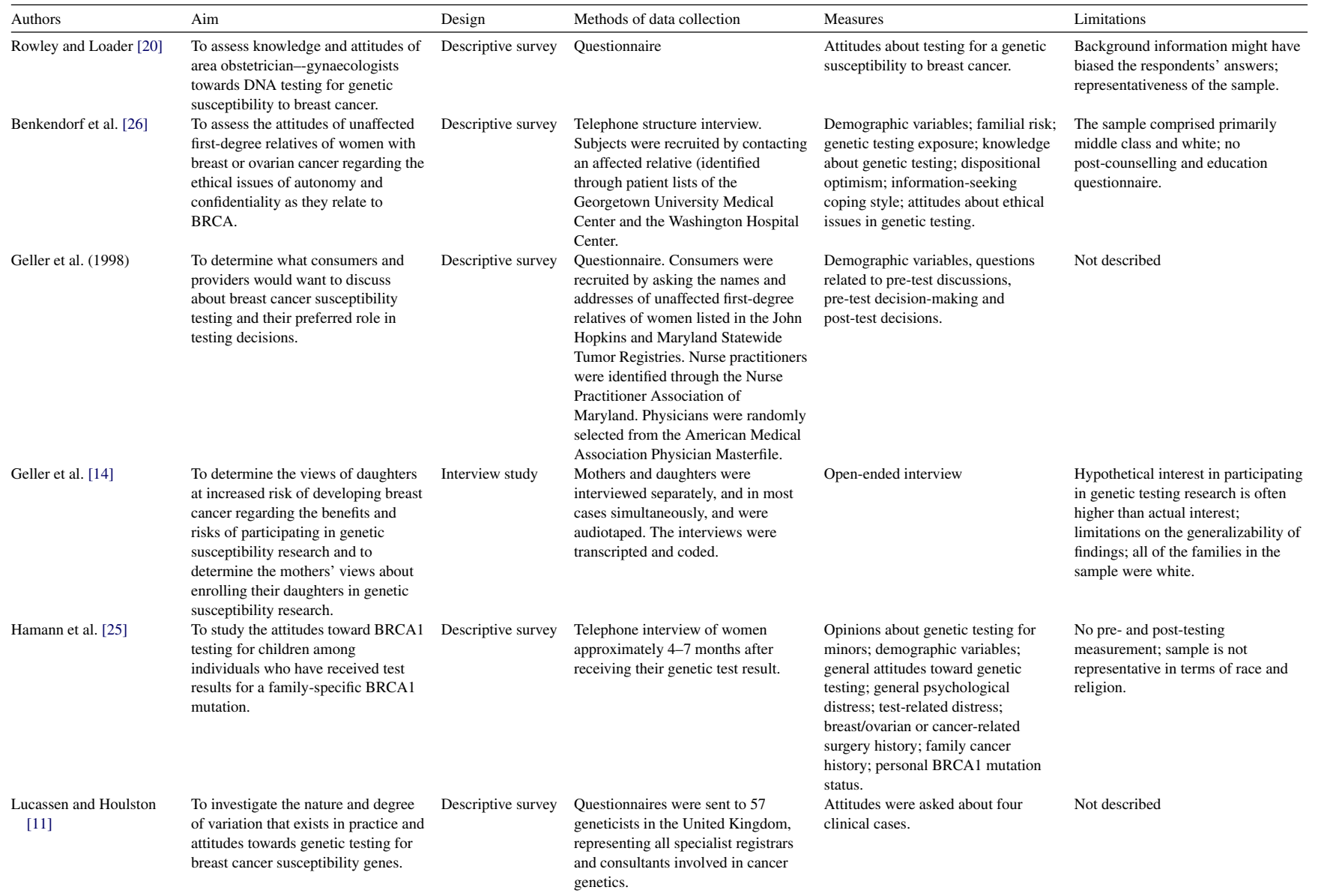


Campbell and Ross [12] To study healthcare professionals' attitudes regarding parental access to and confidentiality of predictive genetic testing of children.

Harel et al. [15]

Welkenhuysen and Evers-Kiebooms [13]

To investigate attitudes of midwives and nurses regarding predictive testing for hereditary breast cancer.

Welkenhuysen and

To investigate the reactions of general practitioners (GPs), nurses, and midwives concerning the cancer

Yumuk et al. (2004)

To identify attitudes toward genetic testing.

To examine adolescents' attitudes towards genetic testing for breast cancer
Interview study

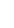

All interviews were recorded and tapes transcribed. Data wer examined qualitatively. Evers-Kiebooms [18] risks in a high-risk family.

Descriptive survey Students were asked to participate in an anonymous survey. Parental or guardian consent was sought. Information about three hereditary disorders was provided. Afterwards the students' attitudes were assessed.

Descriptive survey Mail questionnaires were sent to a sample of midwives and nurses, randomly selected from the membership files of midwife and nursing associations.

Descriptive survey Mail questionnaires were sent to a sample of GPs, midwives, and nurses, randomly selected from the membership files of their respective professional associations.

Descriptive survey A questionnaire was used for subjects at three different hospitals. Nurses and medical students were approached when they were on duty on different floors; oncology patients relatives were surveyed in outpatien chemotherapy unit waiting rooms; non-oncological patient groups were approachec in other outpatient waiting rooms.

Campbell and Ross [17] To explore parental attitudes and beliefs about genetic testing of children for conditions that present throughout the life cycle.

To examine psychological and family Descriptive survey Questionnaires

Cappelli et al. [16] $\quad$ To examine psychological and fa functioning, health attitudes,
beliefs about genetic risks in adolescent females.

Focus group study Focus groups

To examine attitudes of medical

Riordan and Loescher students at a single university towards genetic testing in minors.
Subjects were asked about how they Small sample $(n=25)$; sample was a would respond to families requesting convenience sample. predictive testing for various

conditions, about policy

recommendations as well testing

preferences for their own children

(assuming that they had a positive

family history), about their attitudes

towards questions related to

confidentiality of genetic

information.

Demographic variables, attitudes

towards genetic testing for three

different disorders.

No information about socio-economic background and insurance coverage. Individuals were not at high risk for these conditions. Limited to a population of a suburban high school

Demographic variables, opinions Low response rate from the sub-sample about the acceptability of a predictive of nurses.

test.

Demographic variables, a

hypothetical scenario involving

breast cancer, followed by

open-ended questions.

Demographic variables; attitudes

towards genetic testing.

Low response rate from the sub-sample of nurses.

Not described

Five cases of varying degree of

The focus groups represented a $\begin{array}{ll}\text { controversy were explored, beginning } & \text { convenience sample. Only a few } \\ \text { with the least controversial. } & \text { respondents with personal experience }\end{array}$ with genetic conditions.

Child behaviour checklist; youth self-report form; family assessment measures; breast cancer survey.

Since no genetic testing was

conducted, no correlation can be made with actual genetic risk; small sample further precluded analysis of subtypes based on family history of cancer Sample was limited and possibly biased. 
Table 2

Summary of finding, study population and sample size of included studies

\begin{tabular}{llll}
\hline Authors & Summary of findings & Study population \\
\hline $\begin{array}{l}\text { Rowley and Loader } \\
{[20]}\end{array}$ & $\begin{array}{l}\text { Opinion was divided about the appropriateness of } \\
\text { offering testing to daughters under the age of 18 years } \\
\text { of a woman harbouring a BRCA1 mutation. (23.8\% } \\
\text { strongly agreed, 22\% agreed somewhat, 21.9\% neither }\end{array}$ & $\begin{array}{l}\text { Obstetrician-gynaecologists of all } \\
\text { five Rochester (USA) hospitals }\end{array}$ & Of the 124 area prenatal-care \\
& agreed nor disagreed, and 32.3\% disagreed). & & the presentation and completed \\
& the attitude questionnaire.
\end{tabular}

Benkendorf et al. [26] Most of the women agreed that parents should be able to Women aged 18-75 years with at decide whether their minor children should have a least one first-degree relative with genetic test (32\% agreed strongly and $56 \%$ agreed). breast and/or ovarian cancer and no personal history of cancer.

Geller et al. [37] $\quad 37 \%$ of women, if found to have a susceptibility, would test a 13 -year-old daughter; $32 \%$ of both physicians and nurse practitioners thought it was important to test the 13-year-old daughter of a women susceptible to inherited breast cancer.

Geller et al. [14] The study observed that mothers and daughters had a range of reactions to the prospect of enrolling children and adolescents in genetic susceptibility research; that perceptions of benefits and risks were fairly concordant between mothers and daughters; and that daughters initially identified no risks of participating, but their perceptions of the risks and benefits evolved during the course of conversation.

Hamann et al. [25] Of the 218 study participants, 57 (26.1\%) agreed with the statement that children under the age of 18 years should have the opportunity to be tested for BRCA1 gene mutations, 133 (61\%) did not agree, 21 (9.6\%) either responded that they were not sure or it depends, and $7(3.2 \%)$ either did not know or declined to answer the question. Among the 218 study participants, 104 reported having children under the age of 18 years. Of these 104 individuals, only $18(17.3 \%)$ noted that they would want their own children tested for a BRCA1 mutation, while $(82.7 \%)$ did not endorse this statement.

Lucassen and Houlston [11]

Campbell and Ross [12]

Harel et al. [15]

Welkenhuysen and Evers-Kiebooms [13]

Welkenhuysen and Evers-Kiebooms [18]

Yumuk et al. [38] $34 \%$ (16/47) of the respondents were prepared to offer predictive testing to a 15 -year-old girl asking for a predictive test; $49 \%$ (23/47) were not prepared to do so $15 \%$ (7/47) did not know what action they would take. Regarding the access to presymptomatic genetic testing for breast cancer in adolescents with a family history of the disease, $4 \%(1 / 25)$ of the clinicians would encourage testing, $16 \%$ (4/25) would prohibit testing, $40 \%$ (10/25) would permit testing in all circumstances, and $40 \%$ (10/25) would permit but discourage testing.

Most girls (67\%) wanted to be tested for familial breast cancer. Girls who had a relative with breast cancer were significantly more willing to be tested than were other girls $(78 \%$ vs. $61 \%, p<0.05)$. The main reason given by girls against genetic testing for breast cancer was that knowledge would make them too nervous/stressed. Agreement was higher when a 16-year-old adolescent requests a predictive test for breast cancer (median 5, S.D. \pm 1.22 ) than when parents request predictive testing of their 5-year-old child (median 3, S.D. \pm 1.79 ). $30 \%$ of the GPs and $35 \%$ of the nurses/midwives argued that a 2-year-old daughter at risk for breast cancer is too young for a test. On the other hand, 26\% of the GPs and $30 \%$ of the midwives/nurses thought that a predictive test for the daughter would be useful.

If the survey respondents had an increased cancer risk, $92.7 \%$ would have their children tested.
At-risk women plus nurse

practitioners, and physicians in five specialities in Maryland.

Mothers and daughters from 12 breast cancer families recruited primarily through the Breast Center at Johns Hopkins University.

Individuals who were tested for a BRCA1 mutation and learned their mutation status from a certified genetic counsellor. They belong to an extensive Utah-based kindred of northern European descent with a known cancer-susceptibility mutation in BRCA1.

Clinical geneticists in the United Kingdom who deal with cancer genetics.

Healthcare professionals (geneticists and paediatricians).

Students in grades 10-12 attending a suburban high school in Barrington, Rhode Island.

Midwives and nurses in Flanders.

GPs, nurses, and midwives in Flanders.

Randomly chosen individuals in three different hospitals in Turkey, including patients without cancer, caregivers of cancer patients, senior medical students, and nurses.
238 women, no response rate mentioned.

At-risk consumers: 426/584

(73\%); nurse practitioners: 143/179 (80\%); physicians 296/601 (49.3\%)

12 mother-daughters dyads were interviewed.

218 individuals (133 women and 85 men) participated. No response rate mentioned.

Of 57 geneticists, 47 completed questionnaires were received $(83 \%)$.

13 geneticists from 10 different institutions or practice sites; 12 paediatricians from 9 different institutions or practice sites. No response rate is mentioned.

Of 672 students, 361 completed the questionnaire $(54 \%)$.

Of 119 midwives and 881 nurses, 69 midwives (58\%) and 293 nurses (33\%) responded.

Of 356 GPs, 881 nurses, and 69 midwives, 215 GPs (60\%), 69 midwives (58\%), and 293 nurses $(33 \%)$ responded.

179 individuals participated (38 patients without cancer, 51 caregivers of cancer patients, 35 senior medical students, and 55 nurses). 
Table 2 (Continued)

\begin{tabular}{|c|c|c|c|}
\hline Authors & Summary of findings & Study population & Sample size and response rate \\
\hline $\begin{array}{l}\text { Campbell and Ross } \\
\text { [17] }\end{array}$ & $\begin{array}{l}\text { There was widespread interest ( } 9 \text { of } 11 \text { focus groups) in } \\
\text { testing children for the breast cancer gene. }\end{array}$ & $\begin{array}{l}\text { Randomly recruited individuals in } \\
\text { the suburbs of Chicago. Caucasians } \\
\text { as well as Afro-Americans were } \\
\text { intensively recruited. }\end{array}$ & $\begin{array}{l}12 \text { focus groups comprising } 4-12 \\
\text { respondents. Overall there were } \\
102 \text { respondents ( } 18 \text { males and } \\
84 \text { females). }\end{array}$ \\
\hline Cappelli et al. [16] & $\begin{array}{l}\text { Of the } 55 \text { mother-daughter pairs in which the mother } \\
\text { had been treated for breast cancer, } 76 \% \text { of the } \\
\text { adolescent daughters and } 74 \% \text { of the mothers would } \\
\text { take a BRCA gene test. }\end{array}$ & $\begin{array}{l}\text { Mothers with a previous history of } \\
\text { breast cancer (and a control group } \\
\text { without a history of breast cancer) } \\
\text { and their adolescent daughters. }\end{array}$ & $\begin{array}{l}55 \text { women with a previous history } \\
\text { of breast cancer and } 55 \text { women } \\
\text { without a history of breast cancer. }\end{array}$ \\
\hline $\begin{array}{l}\text { Riordan and Loescher } \\
\text { [19] }\end{array}$ & $\begin{array}{l}47 \% \text { of students would agree to test a } 7 \text {-year-old for a } \\
\text { BRCA1 breast cancer predisposition; } 83 \% \text { would agree } \\
\text { to test a } 17 \text {-year-old for the same disorder. Students who } \\
\text { had already taken a genetics course were less willing to } \\
\text { provide testing to a } 7 \text {-year-old. }\end{array}$ & $\begin{array}{l}\text { Medical students at the University } \\
\text { of Arizona. }\end{array}$ & $\begin{array}{l}\text { Of } 435 \text { students, } 135 \text { completed } \\
\text { the questionnaire }(31.5 \%) \text {. }\end{array}$ \\
\hline
\end{tabular}

[14-16]. The attitudes of healthcare professionals (geneticists as well as paediatricians or obstetricians-gynaecologists) about testing adolescents for breast cancer diverged $[11,12,20]$. For example, a survey of clinical geneticists dealing with cancer genetics in the U.K. showed that $34 \%$ of the respondents would offer predictive testing to a 15-year-old girl whose mother carries a pathogenic BRCA1 mutation, who is mature for her age, and who is well informed about the risks of such a test [11]. Forty-nine percent of respondents would not do so and $15 \%$ did not know what action they would take. The split in opinions is related to the complexity of such a request and the balance between potential harms and benefits. Respondents $[11,12,20]$ have stressed that adolescents have decision-making capacity and are often mature enough to take control of their own healthcare and to request a genetic test for familial breast cancer. Several professional guidelines related to genetic testing in minors already acknowledge the gradual development of a child's cognitive skills and moral reasoning. Although it can be argued that parents' consent for a genetic test is clearly advisable for adolescents, this is legally not always required. In the U.K., for example, the Family Law Reform Act [21] contextualizes the British Medical Association's (BMA) recommendation on genetic testing [22]. In this document, the BMA states that young people between 16 and 18 years old are presumed to be competent to give consent to genetic testing, without any necessity to obtain consent from his/her parent or guardian. As with adults, various professional guidelines clearly recommend for adolescents that predictive genetic testing should only occur after pre-test counselling wherein complete information is provided about the disorder, the value and limitations of the test result, preventive and therapeutic options, and the possible psychological impact of the test. It should also be questioned whether the test request is voluntary and comes from a competent applicant.

The arguments used in favour of providing a predictive genetic test for an adult-onset disease at an adolescent on his request are in line with the general evolution in medicine to take into account the adolescent's maturity and decision-making competence. However, no article included in this review adequately defined these frequently used terms, neither provided recommendations for assessing the psychosocial maturity of adolescents. As well professional guidelines regarding predictive genetic testing do not provide recommendations regarding the assessment of a minor's competence [23]. It is of crucial importance that health professionals who assess competence are skilled and experienced in counselling young patients [24].

Many respondents of the studies reviewed here would probably refrain from requesting a predictive genetic test after being informed of the potential risks of such a test. For many adolescents interviewed in the studies the invitation to participate in a genetic test for breast cancer was a hypothetical situation and was not the result of a careful assessment of the benefits and risks of such a test. This is illustrated by an interview study that showed that all adolescent respondents, regardless of age, responded affirmatively when asked whether they would undergo testing, because the interview focused on non-invasive sample collection rather than on assessment of risks and benefits of the test itself [14]. In addition, a study of individuals who were tested for a BRCA1 mutation and who learned their mutation status from a certified genetic counsellor showed significantly less support for testing [25] than did a survey study of unaffected first-degree relatives of breast cancer patients [26]. A potential explanation for this finding is that individuals who have experienced genetic counselling and testing themselves may be more aware of the potential risks and limitations than those who have not been counselled or tested. This might also explain why relatively many respondents supported genetic testing in minors for an adult-onset condition such as breast cancer, although this is in opposition with the recommendation of the genetic societies regarding genetic testing for late-onset conditions.

Various parents believe that detection in childhood might be advantageous for starting preventive measures and might help prepare their children and themselves psychologically for the future $[17,25,26]$. Therefore, parents often believe they should have the right to give their consent for genetic testing for BRCA in their children. Studies of medical students [19]; obstetricians-gynaecologists [20]; paediatric residents [27]; and medical students, residents, and practicing 
physicians [28] have shown that various healthcare professionals would agree to providing genetic testing for children upon parental request.

The reviewed surveys indicate that various respondents apparently have failed to understand the potential risks related to genetic testing and may have misunderstood the concepts of genetic transmission or neglected to take them into account when considering the genetic testing of minors. A review of professional guidelines [23] indicates that all professional guidelines similarly formulate that predictive genetic testing for adult-onset diseases should only be performed for persons of legal age, except in cases of disorders for which preventive or therapeutic actions could be initiated. This is based on the rationale that medical benefit to the child should be the primary justification for genetic testing. In the cases in which testing is not urgent (e.g., the outbreak of the disease occurs only in adulthood and no therapy or preventive measures can be initiated before that time), it has been stressed that testing should be delayed until the person is old enough to decide for him or herself. This cautious position towards testing of minors has been adopted, because testing minors might harm self-esteem, create depression or anxiety, distort the family perception of a child, or stigmatize a child. Authors have also stressed that testing children can breach the confidentiality $[29,30]$ and the privacy of genetic information [31]. It has also been argued that adolescents are disadvantaged in their ability to make such a complex and potentially life-changing decision by incomplete brain maturation, and associated underdevelopment of executive functions [32]. These findings underscore the need for genetic education and counselling when addressing requests for testing minors. This might help to bring the expectations and assessment of risks to a realistic level. Studies have shown that patients [33] and healthcare professionals [34] that do not have daily involvement with clinical genetics may have exaggerated expectations about genetic testing.

Due to the focus on familial breast cancer, the results of this study cannot be considered representative for other adultonset diseases. Research [13] showed, for example, that the accepability ratings for predictive genetic testing in adolescents for an unpreventable and untreatable disease such as Huntington Disease were less favourable than for preventable and/or treatable diseases. This makes clear that when discussing an adolescent or parental request for a predictive genetic test for an adult-onset disorder various individual elements should be taken into consideration: availability of preventive and therapeutic measures for the disease, severity of the disease, utility of the genetic test, the foreseen onset of the disorder, psychosocial, ethical and legal concerns [35]. A recent study [36] also showed that the majority of clinical geneticists in the USA, Canada, UK, Australia, and New Zealand agreed with existing guidelines regarding predictive genetic testing in minors, but only $15 \%$ cited policy as a reason for refusing such tests. "This indicates that clinicians are making individual judgments, as opposed to simply following suggested recommendations" [36].

\section{Conclusion}

Through our systematic review, we analysed common arguments used in favour of or against predictive genetic testing of minors in the case of familial breast cancer. Although an accurate comparison of the various studies was very difficult due to the varying study populations, study designs, samples sizes, and study measures, our analysis showed that many respondents were not aware of the potential risks related to such testing. Various respondents took a position opposed to the position advanced in professional recommendations.

We also observed a lack of representative studies on geneticists and genetic counsellors, a professional group issuing the most recommendations on genetic testing in minors. Further research should be performed on the attitudes of geneticists and genetic counsellors towards genetic testing in minors and their adherence to professional guidelines on that topic.

\section{Reviewers}

Angus Clarke, Institute of Medical Genetics, Cardiff University, University Hospital of Wales, Heath Park, Cardiff, Wales CF14 4XN, United Kingdom.

Fiona Richards, Senior Social Worker, Department of Clinical Genetics, The Children's Hospital at Westmead, Locked Bag 4001, Westmead, NSW 2145, Australia.

\section{Acknowledgement}

The research for this contribution was supported by the Eurogentest Network of Excellence of the EU, FP6-512148.

\section{References}

[1] King MC, Marks JH, Mandell JB. Breast-ovarian cancer risks due to inherited mutations in BRCA1 and BRCA2. Science 2003;302(5645):643-6.

[2] Lux MP, Fasching PA, Beckmann MW. Hereditary breast and ovarian cancer: review and future perspectives. J Mol Med 2006;84(January (1)):16-28.

[3] Smith RA, Cokkinides V, Eyre HJ. American Cancer Society guidelines for the early detection of cancer. CA Cancer J Clin 2006;56(January-February (1)):11-25.

[4] Committee for Public Relations and Ethical Issues of the German Society of Human Genetics. Statement on genetic diagnosis in children and adolescents. GSHG; 1995. http://www.gfhev.de/en/gfh/.

[5] Danish Council of Ethics. Genetic investigation of healthy subjects. Report on presymptomatic gene diagnosis; 2001. http://www.etiskraad.dk.

[6] European Society of Human Genetics. Provision of genetic services in Europe-current practices and issues; 2001. http://www.eshg.org.

[7] Borry P, Schotsmans P, Fryns JP, Dierickx K. Carrier testing in minors: a systematic review of guidelines and positions statements. Eur J Hum Genet 2006;14(2):133-8.

[8] The American Society of Human Genetics Board of Directors and The American College of Medical Genetics Board of Directors. Points to 
consider: ethical, legal, and psychological implications of genetic testing in children and adolescents. Am J Hum Genet 1995;57:1233-41.

[9] Clarke A. The genetic testing of children Working Party of the Clinical Genetics Society (UK). J Med Genet 1994;31(10):785-97.

[10] American Medical Association. Testing children for genetic status; 1995. http://www.ama-assn.org/.

[11] Lucassen A, Houlston R. Clinical geneticists' attitudes and practice towards testing for breast cancer susceptibility genes. J Med Genet 2000;37(2):157-60.

[12] Campbell E, Ross LF. Professional and personal attitudes about access and confidentiality in the genetic testing of children: a pilot study. Genet Test 2003;7(2):123-30.

[13] Welkenhuysen M, Evers-Kiebooms G. Predictive genetic testing for breast cancer and Huntington's disease: the opinions of midwives and nurses in flanders. Commun Genet 2003;6(2):104-13.

[14] Geller G, Tambor ES, Bernhardt BA, Wissow LS, Fraser G. Mothers and daughters from breast cancer families: a qualitative study of their perceptions of risks and benefits associated with minor's participation in genetic susceptibility research. J Am Med Womens Assoc 2000;55(5):280-4.

[15] Harel A, Abuelo D, Kazura A. Adolescents and genetic testing: what do they think about it? J Adolesc Health 2003;33(6):489-94.

[16] Cappelli M, Verma S, Korneluk Y, et al. Psychological and genetic counseling implications for adolescent daughters of mothers with breast cancer. Clin Genet 2005;67(6):481-91.

[17] Campbell E, Ross LF. Parental attitudes and beliefs regarding the genetic testing of children. Commun Genet 2005;8(2):94-102.

[18] Welkenhuysen M, Evers-Kiebooms G. The reactions of general practitioners, nurses and midwives in Flanders concerning breast cancer risks in a high-risk situation. Commun Genet 2003;6(4):206-13.

[19] Riordan SH, Loescher LJ. Medical students' attitudes toward genetic testing of minors. Genet Test 2006;10(Spring (1)):68-73.

[20] Rowley PT, Loader S. Attitudes of obstetrician-gynecologists toward DNA testing for a genetic susceptibility to breast cancer. Obstet Gynecol 1996;88(4 Pt 1):611-5.

[21] Family Law Reform Act. s8 (1). Age of majority act (NI) art 4 (1); 1969.

[22] British Medical Association. Human genetics: choice and responsibility. Oxford: Oxford University Press; 1998.

[23] Borry P, Stultiens L, Nys H, Cassiman JJ, Dierickx K. Presymptomatic and predictive genetic testing in minors: a systematic review of guidelines and position papers. Clin Genet 2006;70(5):374-81.

[24] British Medical Association. Consent rights and choices in healthcare for children and young people. London: BMJ Books; 2001.

[25] Hamann HA, Croyle RT, Venne VL, Baty BJ, Smith KR, Botkin JR. Attitudes toward the genetic testing of children among adults in a Utah-based kindred tested for a BRCA1 mutation. Am J Med Genet 2000;92(1):25-32.

[26] Benkendorf JL, Reutenauer JE, Hughes CA, et al. Patients' attitudes about autonomy and confidentiality in genetic testing for breast-ovarian cancer susceptibility. Am J Med Genet 1997;73(3):296-303.

[27] Rosen A, Wallenstein S, McGovern MM. Attitudes of pediatric residents toward ethical issues associated with genetic testing in children. Pediatrics 2002;110(2 Pt 1):360-3.

[28] Demmer LA, O'Neill MJ, Roberts AE, Clay MC. Knowledge of ethical standards in genetic testing among medical students, residents, and practicing physicians. JAMA 2000;284(20):2595-6.

[29] Plantinga L, Natowicz MR, Kass NE, Hull SC, Gostin LO, Faden RR. Disclosure, confidentiality, and families: experiences and attitudes of those with genetic versus nongenetic medical conditions. Am J Med Genet 2003;119C(1):51-9.
[30] Kent A. Consent and confidentiality in genetics: whose information is it anyway? J Med Ethics 2003;29:116-8.

[31] Gostin LO. Genetic privacy. J Law Med Ethics 1995;23(4):320-30.

[32] Richards FH. Maturity of judgement in decision making for predictive testing for nontreatable adult-onset neurogenetic conditions: a case against predictive testing of minors. Clin Genet 2006;70(5):396401.

[33] Press NA, Yasui Y, Reynolds S, Durfy SJ, Burke W. Women's interest in genetic testing for breast cancer susceptibility may be based on unrealistic expectations. Am J Med Genet 2001;1 99(2):99-110.

[34] Walter FM, Kinmonth AL, Hyland F, Murrell P, Marteau TM, Todd C. Experiences and expectations of the new genetics in relation to familial risk of breast cancer: a comparison of the views of GPs and practice nurses. Fam Pract 2001;18(5):491-4.

[35] Borry P, Fryns JP, Dierickx K. Predictive genetic testing in children. A clinical-ethical analysis. In: de Bouvet A, Boitte P, Aiguier G, editors. Questions éthique en médicine predictive. Montrouge Editions. John Libbey Eurotext; 2006. p. 89-98.

[36] Duncan RE, Savulescu J, Gillam L, Williamson R, Delatycki MB. An international survey of predictive genetic testing in children for adult onset conditions. Genet Med 2005;7(6):390-6.

[37] Geller G, Bernhardt A, Doksum T, Helzlsouer K, Wilcox P, Holtzman N. Decision-making about breast cancer susceptibility testing: How similar are the attitudes of physicians, nurse practitioners, and at-risk women? J Clin Oncol 1998;16(8):2868-76.

[38] Yumuk P, Gumus M, Ekenel M, Basaran G, Aliustaoglu M, Topal A, Turhal N. Attitude toward genetic testing for cancer risk in Istanbul. Genet Test 2004;8(2):169-73.

\section{Biographies}

Pascal Borry (PhD) works at the Centre for Biomedical Ethics and Law (K.U. Leuven) His main research focuses are on the empirical turn in bioethics, the ethical aspects of evidence-based medicine and genetic testing, and publication ethics. He is also coordinator of the Erasmus Mundus Master of Bioethics.

Louise Stultiëns (MA) worked at the Centre for Biomedical Ethics and Law (K.U. Leuven) on the Eurogentest-project with as main focus patient rights and genetic testing services.

Herman Nys (PhD) is Director of the Centre for Biomedical Ethics and Law (K.U. Leuven). He teaches medical law in the Medical and Law School of the K.U. Leuven. He is the editor of the International Encyclopaedia of Medical Law, a looseleaf review of medical law of many national states. His main research interests are genetics, biomedical research with human beings and end of life.

Kris Dierickx $(\mathrm{PhD})$ is associate professor at the K.U. Leuven (Centre for Biomedical Ethics and Law). His teaching and research focus on the ethics of genetics and reproductive medicine, on empirical ethics, and on the ethics of biomedical research. He coordinates at this moment an EU-funded research project on the ethical aspects of biobanking. 